\title{
Teodor Llorente, cinquanta anys després: Una polèmica entre Joan Fuster i Josep M. Bayarri
}

\author{
Teodor Llorente, fifty years later: \\ A controversy between Joan Fuster and Josep M. Bayarri
}

\author{
J. Àngel Cano Mateu \\ j.angel.cano@uv.es
}

Universitat de València

\begin{abstract}
Resum: Aquest article analitza la polèmica generada en la premsa valenciana l'any 1961 entre Joan Fuster i Josep M. Bayarri, arran del cinquantenari de la mort de Teodor Llorente. Mentre que Fuster reclama un debat intel lectual al voltant del líder de la Renaixença valenciana i, de retop, dels referents propis, Bayarri en té prou amb commemoracions i celebracions, com misses, lectures de poemes o articles de diari. Aquest enfrontament dialèctic amaga dues maneres totalment oposades d'entendre el valencianisme de postguerra: d'una banda, un valencianisme que proposa l'autocrítica i la reflexió; d'una altra, un valencianisme o «regionalisme» irracional, de caire sentimentalista $i$ antiintel lectual. L'article analitza, doncs, el posicionament i l'abast de la defensa de Llorente per part d'aquests dos autors.
\end{abstract}

Paraules clau: Teodor Llorente, Joan Fuster, Josep M. Bayarri, valencianisme, postguerra.

\begin{abstract}
This paper analyses the controversy that Joan Fuster and Josep M. Bayarri create on the Valencian press in 1961, as a result of the fifty years after Teodor Llorente's death. Whereas Fuster demands an intellectual discussion about the leader of the Renaixença in Valencia and the Valencian writers, Bayarri settles for commemorations and celebrations, masses, poetry readings or journal articles about him. This dialectic confrontation conceals two totally opposed ways of understanding the Valencianism of the postwar period. On the one hand, there is a Valencianism that proposes a self-criticism and a reflection; on the other hand, we find a Valencianism or an irrational «regionalism» that is sentimentalist and anti-intellectual. Therefore, this essay analyses the points of view about Llorente made by these two authors.
\end{abstract}

Keywords: Teodor Llorente, Joan Fuster, Josep M. Bayarri, Valencianism, postwar period.

\footnotetext{
* Vull fer constar que aquest treball s'ha beneficiat de l'Ajuda del Programa de Formació de Professorat Universitari (FPU) del Ministerio de Ciencia, Innovación y Universidades.
} 


\section{En la mort de Teodor Llorente}

Teodor Llorente Olivares, el gran patriarca de la Renaixença valenciana, va morir el diumenge 2 de juliol de 1911 a la seua casa de València. Segons ens conta el fill, Teodor Llorente Falcó, fou «a les 3'45 de la matinada sentat en un sillo i rodejat de sa muller, els fills, el canonge Sanchis i Sivera i el Baró d'Alcahalí», sembla que per l'agreujament de la feridura que sofrí al mes de febrer (1930: 351). El juny de l'any anterior, però, ja havia patit un primer atac d'hemiplegia, el qual havia estat apaivagat, això sí, pels metges (Roca 2007a: 382).

Moltíssima gent, provinent de tots els grups socials, sortí al carrer per acompanyar el cos del poeta i director honorari de Las Provincias, com ens relata l'extensa crònica del soterrar que va ocupar, juntament amb l'esquela, la portada d'aquest mateix periòdic l'endemà del traspàs, el 3 de juliol:

\footnotetext{
Todas las clases sociales se asociaban á la manifestación de duelo, y ella, tan imponente, ofrecía ese carácter de generalidad en donde todos los hombres se unen ante el dolor. Prelado, autoridades militares y civiles, jerarquías sociales, modestos obreros, gentes del campo, formaban larguísimo y nutrido conjunto, último homenaje que con todo el corazón tributaban al poeta sus paisanos (1911: 1).
}

La gentada ocupava -tenint com a punt de partida la plaça de Sant Agustí- tot el carrer de Sant Vicent, «y no se veía aún el final de aquel cortejo», cosa que és «la mejor prueba de la imponente manifestación, en donde [...] todas las clases sociales, todos los elementos de Valencia, acudían para unir su testimonio de dolor y su consideración más respetuosa y más afectuosa en memòria del ilustre finado» (1911: 1). Destaca, a més, el tractament que tingueren les autoritats envers Llorente, atés que era cronista de la ciutat i regidor honorari de l'Ajuntament de València, raó per la qual l'alcalde, Ernesto Ibáñez Rizo, participà activament en la preparació del soterrar del poeta, i hi acudiren els treballadors de l'Ajuntament i la corporació municipal, a més de la banda municipal (1911: 1).

Foren innombrables les personalitats que en conformaren la comitiva: regidors, com Dupuy de Lome, Ibáñez Sánchez o Marco Bori; diputats, com Hernández Lázaro o el marqués de Colomina; l'arquebisbe Guisasola; el capità general, el comte del Serrallo; el president de l'Audiència, Cándido Rodríguez de Celís; el governador civil, Joaquín Moreno; el governador militar, Ximénez de Sandoval; el rector de la Universitat, José Machi; Gonzalo Salvá com a representant de l'Acadèmia de Belles Arts de Sant Carles; el propietari d'El Mecantil Valenciano i degà de la premsa, Francisco Castells; el canonge i confessor, José Sanchis Sivera; el president de la societat Lo Rat Penat, Vicente Dualde, o el pare Ángel, franciscà i director espiritual del finat, entre molts d'altres. Per no parlar dels distingits noms que la crònica reporta, com: el comte de Montornés, Federico Trénor; el president i el secretari de l'Ateneu Mercantil; els comtes de Berbedel i de Trigona; el president del Círculo Liberal-Monárquico; el director de la Societat Econòmica d'Amics del País i senador del regne, Rafael Rodríguez de Cepeda; els cònsols i vicecònsols de països com Veneçuela o Uruguai; representants de la Sociedad de Autores Españoles, com Manuel Iranzo, Eduard Martínez Ferrando 
o Vicente Escalante; directors i redactors de diferents periòdics, i un llarg etcètera que ocupa tres columnes de la crònica i que es clou amb l'esmentada banda de música, el cotxe fúnebre i diversos carruatges (1911: 1).

A més de Las Provincias, la gran majoria de periòdics valencians, com La Voz de Valencia, el Diario de Valencia, El Pueblo o El Mercantil Valenciano, també li dedicà elogis i lloances, així com la premsa catalana i balear, com el Diario de Barcelona, La Vanguardia, la Ilustració Catalana, la Revue Catalane o el Correo de Mallorca. Fins i tot fora de les nostres fronteres lingüístiques, El Noticiero Sevillano, El Defensor de Granada o el Butlletí del Centre Català de Saragossa tingueren condolences per al poeta (Roca 2011).

Per la seua banda, arribaren també records per part de molts escriptors, com les paraules de Vicente Blasco Ibáñez per al Círculo Valenciano de Buenos Aires - del qual, dit siga de passada, ambdós escriptors foren presidents honoraris- (Roca 2007a: 167-168), o d'altres de nord enllà, com és el cas del seu amic Frederic Mistral, que, des de Maillane (Provença), escrigué aquesta lletra de condol el 3 de juliol (Llorente Falcó 1930: 351):

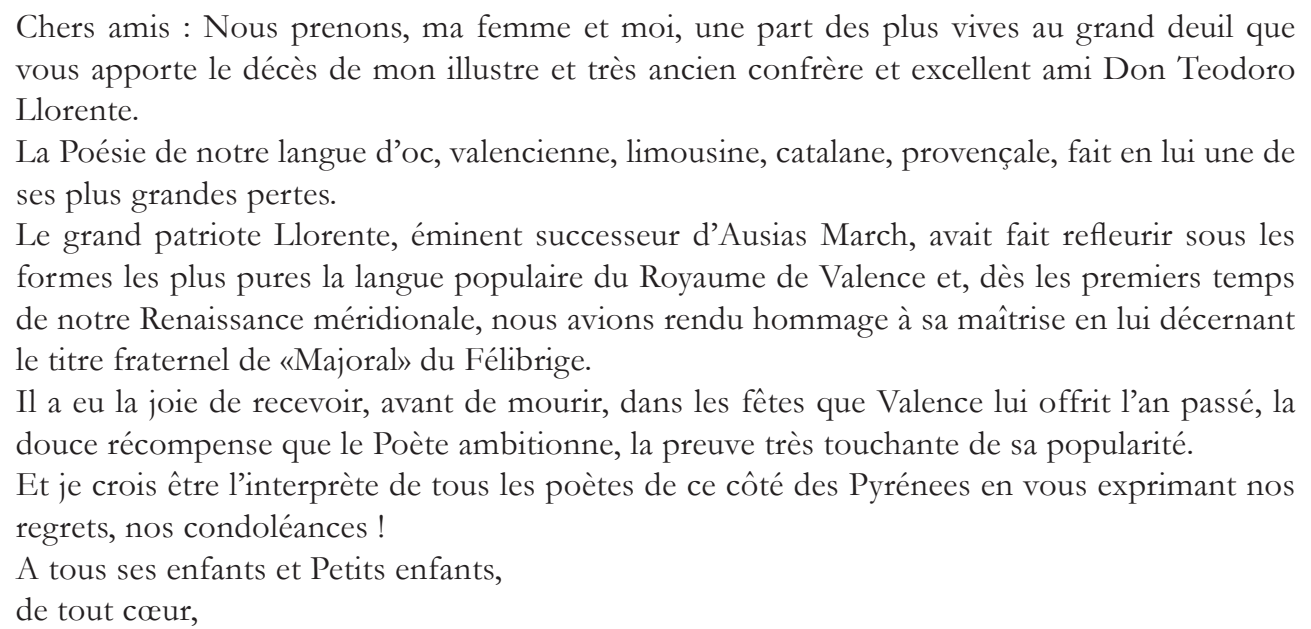

F. Mistral.

Convé recordar, però, que aquesta «maîtrise» que tenia clarament entre el felibrisme, també la tingué - evidentment- entre nombrosos escriptors valencians, tan coetanis com posteriors. Joan Fuster explica, en la introducció de l'Antologia de la poesia valenciana (1900-1950), que «la poesia valenciana prolonga l'herència de Teodor Llorente en allò que aquesta, desarqueologitżada, significa de lleialtat a la terra, i en tant que la terra és carn i ànima, comarca i emoció», justament quan es desenvolupa l'avantguardisme i apareixen noves tendències (1994: 52). De fet, titlla els seguidors del Patriarca com «poetes llorentinistes», la majoria dels quals, encara que van incorporant modalitats líriques pròpies de l'època, mantenen l'idealisme romàntic anterior: 
Ho imposa la seua relació, per raons d'edat, amb les successives promocions de 1909, de 1930 i de la Postguerra: alguns ja s'ajustaren en les publicacions de Bayarri; d'altres foren companys dels avantguardistes; no falta qui, últimament, s'haja acostat a l'estètica intel lectualista de Xavier Casp. De tota manera, l'essencial en ells és allò altre (1994: 52).

«Allò altre», és a dir, la preferència per cantar la terra; el que més endavant etiquetarà com a «paisatgisme sentimental», $\mathrm{o}$, en altres paraules, la idealització romàntica del paisatge (1994: 55). Al capdavall, continuava la línia que havia encetat uns anys abans Manuel Sanchis Guarner, segons el qual, «els poetes valencians de les dues primeres dècades de segle» podien ser classificats amb el terme «pairalistes» (1968: 47). Vicent Simbor, per la seua banda, ens recorda que el mateix any de la mort del poeta, el 1911, aquest publicà «Als poetes jóvens», un poema que pretenia funcionar com un conjunt de pautes que els poetes valencians havien de seguir, així com «un atac contra les perilloses desviacions modernistes» (1988: 44). Simbor mateix en destaca «el llarg i, massa vegades, aclaparador mestratge de Llorente» (1988: 46), en referència al problema que tingueren les innovacions poètiques a l'hora de calar entre els poetes del País Valencià. Més encara, en un altre paper més recent, Simbor remarca «una peculiaritat ben singulan» de la literatura catalana contemporània escrita i publicada al territori valencià: «'ombra tan allargada de Llorente, envigorida generació rere generació pels èmuls, infatigables, del líder renaixencista» (2012: 109). A més, apunta que, malgrat que Carles Salvador i Enric Navarro Borràs foren dos defensors de l'avantguardisme, proclamaren la necessitat de tornar a Llorente (2012: 109). Salvador, en la conferència «Llorente i els infants», de 1948, editada i comentada detalladament per Gonçal López-Pampló, demanava «tornar a Llorente per a llegir-lo atentament, estudiant-lo com en una càtedra de Poesia» (López-Pampló 2012: 172).

Amb tota aquesta breu exposició de dades i fets, el lector s'haurà pogut fer una idea aproximada de la importància que tingué el poeta Teodor Llorente, tan cívicament com literàriament, i sobretot -encara que no tan sols-, al País Valencià. Ens hem deixat actes com l'homenatge de Lo Rat Penat i l'Ateneu Científic, Artístic i Literari el juliol de 1903, que consistí en «un banquete popular, al que acudieron más de trescientos comensales y gran número de corporaciones y sociedades, lo mismo que todos los periódicos de la localidad» (Sanchis Sivera 1911: 312), o la coronació com a «Poeta de València» el novembre del 1909, «una festa que comptà amb el suport i l'adhesió de tota la societat valenciana» (Roca 2007a: 165). Volíem centrar-nos, únicament, en la gran influència que encara ostentava en el moment de la mort i en els anys posteriors. Ara bé, què quedava d'aquell fervor per Llorente just quan se'n commemorava el cinquantenari del traspàs?

\section{El cinquantenari de la mort de Teodor Llorente a través de Joan Fuster i Josep M. Bayarri}

Joan Teodor Corbín Llorente explica a la presentació de l'Obra Valenciana Completa del patriarca que, quan al 1961 feia cinquanta anys de la mort del poeta, hi hagué articles commemoratius en la premsa valenciana, amb un especial interés pels de Las Provincias. Igualment, entre els actes que s'esdevingueren, destaca la festa de l'associació Amigos de la Poesía, en què, a més de recitar-s'hi 
poesies llorentines, s'hi presentà el poemari de Josep M. Bayarri titulat Cinquantenari llorentí (2013: 22). Comparats tots aquests esdeveniments amb els ocorreguts quan el 1936 se'n complien els cents anys del naixement i els vint-i-cinc de la mort, que van comptar, entre altres, amb un fullet dedicat a Llorente aprovat per l'Ajuntament de València, una conferència de Vicent Calvo Acacio a l'Ateneu, l'edició de l'Àlbum homenatge a Teodor Llorente, per part de Lo Rat Penat o la Societat d'Amadors de les Glòries Valencianes, entre d'altres entitats, la biografia que publicà Miquel Duran de València a Barcelona, o els intents de Llorente Falcó de publicar una edició més completa de les poesies del pare o els cinc volums de l'Epistolari Llorente, frustrats per la Guerra Civil (2013: 21), els de 1961 semblen, més aviat, pobres. Bé és cert que el 1936 hi confluïen dues efemèrides, però el balanç no sembla molt afalagador un quart de segle després, més encara si tenim en compte tot el que representava el poeta i la passió que havia despertat només cinquanta anys abans.

\section{1. «E1 cas don Teodor» o una atonia literària}

Joan Fuster s'adonà d'aquesta anomalia, i el 6 de juliol del 1961 en reflexionava a les pàgines del diari vespertí de València Jornada, en l'article titulat, precisament, «Llorente». Per al suecà, el poeta valencià ja feia setanta anys que havia mort, és a dir, que havia arribat al seu apogeu literari i social: ho havia donat tot gairebé cap al 1890. Aquesta distància temporal, doncs, li permet formular-hi la pregunta: «què hi ha de viu i de mort en l'obra llorentina, quina perduració efectiva ha tingut la seua labor literària i cívica, com ha estat assumida la seua herència per la posteritat» (1961a: 2). Fuster, que posa sobre la taula el debat al voltant de la figura de Llorente justament cinquanta anys després del seu decés, apunta, de manera significativa, el poc interés que ha despertat l'efemèride i el poeta entre els mateixos escriptors valencians, més enllà d'uns pocs nostàlgics que li retran una missa i llegiran poemes en el seu honor. Però, al capdavall, «la memòria del pobre Llorente es quedarà sense el tribut que se mereix», segurament, afirma, "perquè no queda ni memòria» i perquè «Llorente, en 1961, és, per a la majoria dels valencians, un nom que no vol dir res o que no diu quasi res», mentre que «per als literats valencians, encara, no és molt més... » (1961a: 2).

Al seu parer, ni l'obra poètica ni el seu paper com a «home de renaixença» han tingut un pes determinant per al país, atés que va «fallar»-i ho posa entre cometes ell mateix- com a líder del moviment (1961a: 2). ${ }^{1}$ Per aquesta raó, és conscient -no pot saber què haguera passat en cas contrari- que «amb la seva mentalitat de diputat silvelista, amb la seua concepció municipal del País

1 Aquesta serà la visió negativa entorn a Llorente i la Renaixença valenciana de la majoria d’intel lectuals dels anys 60 i 70, com Manuel Sanchis Guarner, Ricard Blasco, Alfons Cucó o el mateix Joan Fuster, que en parlaran constantment de «fracàs», «folklorisme» o «apoliticisme» (Roca 2007b: 411). En l'actualitat, els estudis dels professors Vicent Simbor (1996) o Rafael Roca (2007a, 2007b), sobretot, han demostrat que la Renaixença valenciana va fer el que podia fer en un context sociopolític i cultural com el valencià de finals del segle XIX i principis del XX, totalment diferent al que s'esdevenia al Principat. 
Valencià i amb la seua estètica anacrònica» no podia garantir-se una posteritat entre els escriptors futurs. Però Fuster hi assota també els intel lectuals autòctons per no haver-se'n responsabilitzat, ni que només fora per debatre el que ell anomena «cas don Teodor». Ell mateix -que, no ho oblidem, és qui pretén iniciar el debat sobre aquest «cas»— també s'inclou en aquest «nosaltres»: «Un mínim de respecte havia d'haver-nos impulsat, a tots, a prestar-li una forma o altra d'atenció efectiva» (1961a: 2), però lamenta que no ho han fet, com sol ocórrer «amb una freqüència sospitosa». L'adjectiu només pren tot el significat gràcies a la pregunta retòrica que el segueix: «A cinquanta anys de la mort de Llorente, aquesta atonia "literària", ¿no té tot un valor de símbol?» (1961a: 2).

Per a Joan Fuster, l'oblit de la classe intel lectual valenciana -amb excepcions aillades, com veurem tot seguit- cap a Llorente, que havia estat durant anys el gran líder literari, social i polític, simbolitza la deserció de la nostra intel lectualitat cap als referents propis. Si no s'ha posat el focus sobre la figura més influent en el «valencianisme»-si podem emprar aquesta etiqueta- de finals del segle XIX i principis del XX, sobre quina altra personalitat valenciana es posarà? El de Sueca, però, encara apunta que, per sort, «les confiances del país i de la posteritat renaixentista tenen d'altres seguretats» que no dependrien dels escriptors ni del patriarca, el qual, recordem-ho, serà criticat pel mateix Fuster o per Sanchis Guarner per no haver sabut o no haver volgut atorgar un caire polític al moviment al País Valencià (Roca 2007b: 411).

Fuster, doncs, aprofitava l'efemèride dels cinquanta anys de la mort del poeta, «el cas don Teodor», per posar sobre la taula el vertader debat de fons: la falta d'esperit crític i la negligència dels nostres intel lectuals cap a les figures pròpies, cosa que no deixava de ser simptomàtica d'una societat acrítica, irreflexiva, panxacontenta, desmemoriada o meninfotista com la valenciana en un període com els anys seixanta; una societat subjecta, al capdavall, al «regionalismo bien entendido». L'article de Fuster rebé resposta més de tres mesos després, concretament, el 14 d'octubre de 1961, en forma de carta al director des de les pàgines de Las Provincias; la signava Josep Maria Bayarri i portava un títol suggeridor: «Encara Llorente, i... sempre».

\subsection{El disgust, o «disgustet», de Josep M. Bayarri}

El 1961, com hem indicat adés, Josep M. Bayarri va publicar el poemari Cinquantenari llorentí. No cal incidir en el caràcter elegíac i panegíric cap al «mestre Llorente», cap al «pare Llorente» (1961a: 5) de l'obra, ni en l'exaltació d'una «omnitut llorentina» (1961a: 35) que ho impregnava tot. Tampoc no és casual que l'últim poema porte per títol «Fidelitat» i cante «Dels Teodòrs Llorente / la gloriosa niçaga / -cultura, poesia- / dilècta i valenciana.... ${ }^{2}$ o que recorde una nit a l'Hotel Munich, quan

2 Josep M. Bayarri defensà, durant els anys vint, una proposta gramatical del valencià per tal de diferenciar-se del català, la qual es basava en una espècie de transcripció fonètica de la pronunciació apitxada, lluny, això sí, de raons científiques. Per a Vicent Simbor, fou una sort que ningú no li fera cas, de manera que abandonà la idea i seguí l'ortografia normalitzada; no obstant això, en els anys seixanta hi tornà a la càrrega (1988: 138). En el conjunt dels escriptors 
«fon sa ma [la de Llorente] entre les meues / com “FEureka!” en mon ànima» (1961a: 43-44). A jutjar pels versos de Bayarri, Llorente seguia sent tot un referent, un autèntic ídol -si més no, per a ell.

Per això, l'octubre d'aquell mateix any, tres mesos després de l'article de Joan Fuster, no es pogué estar de respondre amb l'«Encara Llorente, i... sempre», que traspuava un marcat to d'enuig vers al suecà embolcallat de retòrica. El poeta valencià se sent disgustat («disgust» $\mathrm{O}$ «disgustet», matisa) per les paraules que l'assagista ha dedicat al cinquantenari del traspàs de Llorente, i s'estranya, tot i que entre parèntesis, que aquestes hagen aparegut al periòdic Jornada, un periòdic, com destaca, de la ciutat de València. Potser, en la ment de Bayarri, el qual interpretarà com un atac l'article fusterià, no cabia que la premsa de la mateixa capital poguera fer públiques declaracions en què es qüestionara el patriarca. Al parer de l'autor d'El perill catalá, havien estat -no podia ser d'una altra manera- uns «comentaris pesimistes, depriments, amargs, injusts» que subestimaven «la figura e l'òbra de Llorente gratuïtament, en evident punible llaugerea», raó per la qual, amb la paràfrasi d'uns mots de Nicolau Primitiu, acusa Fuster de no saber crear «adeptes» per parlar «als valencians que demòstren la seua valencianitat i l'interés per la seua llengua [...] d'una manera aspra, pòc mestrívola i quasi insultant» (1961b: 7).

L'article ja no abandonarà aquest to de desqualificació personal del «pululant escriptor» que, en opinió de Bayarri, és Joan Fuster. En primer lloc, el poeta valencià dubta del suposat pesar de Fuster per la poca importància que s'ha dedicat al patriarca. A més, li recrimina, amb una maniobra més per desautoritzar-lo, que el vers que el suecà havia apuntat com a argument per a demostrar que Llorente ja havia donat el millor de si mateix el 1890 ( $(S$ Soc el qui Deu consagra excèls poeta», diu Bayarri, tot i que Fuster havia escrit «Soy el que Dios consagra excelso vate») no és un decasíl lab, sinó, en realitat, un hendecasíl lab. Tot seguit, fa una defensa en forma d'enumeració de tot el que Llorente escrigué, realitzà i publicà a partir dels 54 anys, «quan acava de ser empresonat per sa valentía i idoneitat periodístiques» ${ }^{3}$ (1961b: 7).

Bayarri, dins d'un «nosatros» que, evidentment no inclou Fuster, es desmarca dels «intel lectuals» que «han fallat», dels que «han manifestat la pròpia atonia "literaria" desertant amb freqüències sospitoses», d'aquells «quatre gats (i no obstant, de vèsta plumífera epicena?!)», i es reivindica entre els que Fuster havia encunyat com a «quatre o cinc senyors, lletraferits enyorívols» que li han retut misses o li han recitat poemes elogiosos (1961b: 7). Igualment, recorda que l'any del cinquantenari

valencians posteriors al 1939, el cas de Bayarri només rep la categoria de simple anècdota, atés que pràcticament tots adoptaren les Normes de Castelló de 1932 (Carbó i Simbor 1993: 28). Nosaltres, ací, transcriurem literalment els textos en la seua particular ortografia.

3 Segons Rafael Roca, un dels màxims especialistes en Teodor Llorente a qui agraïm des d'aquestes línies la següent informació, Llorente no hauria arribat a estar empresonat, al contrari del que escriu Bayarri. Com ens conta l'estudiós, al setembre de 1888, Teodor Llorente i Ramir Ripollés -directors, respectivament, dels diaris Las Provincias i El Correo de Valencia- van ser processats per haver publicat un telegrama que reproduïa un testimoni fals; el jutge que els processà demanava presó per a ells. La petició, però, no estava suficientment justificada (entre d'altres coses, perquè el telegrama havia sigut redactat per una agència de Madrid, que fou qui el divulgà) i, finalment, quedà en no res. 
encara no ha acabat, i que hi ha més actes programats, ja que no creu que existisca aquella «atonia» entre els valencians. També aprofita - de passada- per criticar com a «horrible expressió antivalenciana!» l'etiqueta «País Valencià», alhora que explica que ells, el «nosatros», s'identifiquen amb la fe i l'amor del lema dels Jocs Florals, sense fer, però, referència a la pàtria (1961b: 7). Per acabar la seua rèplica, utilitza una cita del mateix Fuster extreta de l'Antologia de la poesia valenciana (1900-1950), a fi de fer-li veure el que havia apuntat anteriorment, com si fora una contradicció criticar un aspecte de Llorente però agrair-li'n un altre:

I així [identificats en fe, amor...] evoquem Llorente, perque no volem ser malnaixcuts ni titllats desagraïts envers aquells que «van respondre al problema del moment $\mathrm{i}$ als quals devem la possibilitat d'estar nosaltres, escriptors i poetes valencians en el lloc on estem» (1961b: 7).

L'últim paràgraf, totalment prescindible des del punt de vista informatiu, és una prova més d'aquesta passió incondicional -i, per tant, irracional- de Bayarri cap al patriarca: «Total que Llorente, sens emfasi. "Es qui Deu consagrà poeta excèls!"» (1961b: 7).

El caràcter i el to d'aquesta resposta del poeta valencià donen a entendre que l'article fusterià degué caure com una bomba entre Bayarri i el seu grup; aquest se'ns mostra molt ofés perquè Fuster haja tocat una figura com Llorente i perquè considere que, al capdavall, malgrat tots els actes que s'hi han celebrat, no s'hi haja reflexionat sobre la desmemòria de la majoria dels valencians cap a aquest personatge que fou tan important només mig segle abans. La realitat, però, és que Josep M. Bayarri sembla haver-se quedat en la superfície del problema apuntat pel suecà, i no ha fet més que manifestar justament el que aquest criticava. Bayarri, en certa manera, ha demostrat que, efectivament, al patriarca només el coneixen «quatre o cinc senyors, lletraferits enyorívols», a pesar que critique l'altre sector -per dir-ho d'alguna manera-, on hi hauria Fuster, de vestir una «vèsta plumífera epicena», és a dir, d'elitistes, d'apartats de la societat. L'assumpte encara donaria peu a un nou article de Fuster gairebé una setmana després.

\subsection{Fuster, «llorentinòfil» $\mathrm{i}$ «criniller»}

El 20 d'octubre de 1961, Joan Fuster publicava, de nou al diari vespertí Jornada, una resposta a Josep M. Bayarri, i la titulava «Defensa de Llorente». Començava remarcant que el primer article d'aquesta polèmica («Llorente»), era simplement «un paper inofensiu i predominantment elegíac», raó per la qual se sorprèn que tres mesos després el poeta valencià hi proteste, i, a més, «amb una irritació i una mala bava que m'honoren» (1961b: 2); per al suecà, que també entrarà en el desprestigi de l'adversari, que Bayarri es mostre contrariat amb una opinió és un indicador totalment positiu:

En la seua llarga i pintoresca vida intel lectual -diguem-ne intel lectual-, el senyor Bayarri no n'ha encertat ni una: ha tingut l'estranya habilitat de defensar sistemàticament les actituds més absurdes, més equivocades o més improcedents. Per això cal tenir en compte la seua opinió: 
quan ell aprova malament; quan ell discrepa, segur que anem pel millor camí possible. És una pedra de toc oportuna i que no falla mal (1961b: 2).

La consideració de Fuster cap a l'article de Bayarri és la d'una més de les seues «"xarlotaes" que haurien estat genialment còmiques si no haguessin estat tan fora de lloc», com la seua peculiar proposta ortogràfica o el llibre El perill catalá, ${ }^{4}$ que cerquen el «cultiu del confusionisme i de la tergiversació» (1961b: 2). Quant a Llorente -que és, al capdavall, el motiu central de la polèmica-, Fuster reitera el que ja havia dit anteriorment, que «el vell patriarca renaixentista es repetia d'una manera trista i supèrflua», un comentari no exempt d'una mica de malícia cap a Bayarri, a qui titlla de desconeixedor de l'obra del darrer Llorente (1961b: 2).

Tot seguit, el de Sueca torna a valorar, des del punt de vista social, la Renaixença valenciana, que fracassà, com ho demostren fets com que els joves de 1911 -entre els quals, hi estaria el mateix Bayarri- hi reaccionaren en contra o la displicència de la societat valenciana davant una efemèride com el cinquantenari llorentí. Fuster acusa els renaixencistes autòctons per la falta de mobilització cívica, i, per tant, per les conseqüències que se'n derivaren i que encara hi són patents. A més, davant la falta d'esperit autocrític per part de Bayarri, l'assagista no fuig d'estudi i reconeix que aquestes «nostres "desgràcies" col lectives no sempre són dels altres» (1961b: 2).

Fuster centra ara l'atenció en l'homenatge a Llorente realitzat per Bayarri i altres escriptors recordem: una missa, lectura de poemes, etc. Per al suecà, no ha estat suficient; l'assagista demana una exigència més gran en una figura com la del patriarca, demana «més homenatge». Per aquesta raó, es reconeix més «llorentinòfil» que Bayarri, a qui lamenta «regatejar-li un tal honor» (1961b: 2). I aquesta és, en realitat, la qüestió principal de la polèmica: ¿qui mostrava més respecte i més memòria cap a Llorente, Joan Fuster, que reclamava que s'hi reflexionara, que es debatera per què la societat valenciana en la seua majoria es presentava indiferent a l'efemèride del cinquantenari de la seua mort, o Josep M. Bayarri, que s'acontentava amb actes concrets i puntuals, efímers en gran part -una missa, una lectura de poemes-, que segurament acabarien en l'oblit fins a un nou «any Llorente»?

L'article acaba amb alguns matisos a les anteriors afirmacions de Bayarri. En primer lloc, Fuster el corregeix, ja que havia catalanitzat el vers llorentí «Soy el que Dios consagra excelso vate», alhora que recalca que, en mètrica catalana, és un decasíl lab, no un hendecasíl lab com li havia apuntat. En segon lloc, obvia les desqualificacions cap a l'expressió «País Valencià», i, finalment, s’hi mostra

4 El perill catalá, de Josep M. Bayarri, és un assaig en què, més que destil lar anticatalanisme, hi escriu contra el pancatalanisme; de fet, en la dedicatòria té unes paraules per a «tots els fraterns amics de la gloriosa Catalunya» (1931: 9). Però, per a Bayarri, aquest «perill, que diem catalá, per a nostra Valencia consistix [...] en creure i propalar que Valencia, l'antic reine, la nostra Patria és catalana, que Valencia, per sí, no té personalitat nacional; que la patria dels valencians és diu Catalunya» (1931: 23-24). 
encuriosit per un mot desconegut que Bayarri li havia etzibat en l'article anterior: «crinillen», ${ }^{5}$ que no ha aconseguit trobar en cap dels «diccionaris més restringidament regionals» (1961b: 2). Aquesta serà, doncs, l'última intervenció del suecà en aquest intercanvi d'opinions aparegudes en la premsa valenciana al voltant de les commemoracions pel cinquantenari del traspàs del patriarca -tot i que no serà l'última polèmica que mantindrà amb Josep M. Bayarri.

\subsection{El darrer comentari de Bayarri}

Josep M. Bayarri no volgué callar i encara publicà un darrer article, ara a Jornada també, sota el títol «Commemorant Llorente», el 25 d'octubre d'aquell mateix any. De fet, els redactors del diari vespertí de la ciutat de València l'emmarcaren, per si hi havia algun despistat que no n'estiguera al cas, en aquesta polèmica: «El poeta José María Bayarri, en contestación al artículo que, bajo el título de "Defensa de Llorente", públicó nuestro colaborador Joan Fuster, el viernes pasado, nos envía el siguiente comentario» (1961c: 6).

Bayarri abandona, però, el to hostil cap a Fuster, i simplement enumera els diferents actes que s'han fet $\mathrm{i}$ que es faran en homenatge a Teodor Llorente. Primerament, recorda el paper que han tingut en aquesta efemèride els diaris («car ell fon un gran periodista»), els intel lectuals («puix el Mestre ho fon reeixidament»), els poetes (amb una cita de Carles Salvador en què el tracta de «figura primordial de la poesía moderna valenciana») i l'atenció de la societat valenciana -cosa que li discutia Fuster (1961c: 6). El poeta, però, repeteix de nou les paraules del suecà extretes de l'Antologia de la poesia valenciana (1900-1950), que ja havia utilitzat en l'article anterior («Encara Llorente, i... sempre»), en què aquest explicitava que gràcies a Llorente i els renaixencistes podien els lletraferits valencians d'aleshores continuar existint com a tals. És l'única vegada que hi apareix el nom de l'assagista, i se'ns presenta com una cita a mode d'argument per tal d'avalar el discurs de Bayarri; ara bé, no hi ha cap apel lació directa -segurament, perquè també era una manera de tancar aquella polèmica.

Malgrat la pèrdua d'intensitat i d'acritud en el discurs de l'autor d'El perill catalá, la resposta era clara: hi ha molts esdeveniments que ja s'han realitzat -recitals poètics, visita al monument, premis amb tema llorentí en els concursos dels Jocs Florals, articles als diaris, etc.-, però també n'hi ha que queden per realitzar, en aquest any d'homenatge al patriarca, per poc que li semblara al de Sueca. Tanmateix, és clar que el que pretenia Bayarri era fer-li veure que escriptors i poble sí que recordaven Llorente. I, encara, retorna sobre el vers de «Soy el que Dios consagra excelso vate» -ara sí, ja en castellà-, el qual segueix considerant un «sublim» hendecasíl lab (1961c: 6). Bayarri

5 Al Boyer's French Dictionary (1839) o al A new and complete French and English and English and French dictionary, on the basis of the Royal dictionary English and French and French and English (1845) apareix «criniller» com a verb en francés, sinònim de «querollen» o «querellen», i com a definició del verb anglés (que té la mateixa forma com a substantiu que com a adjectiu) «scold», això és, «renyar, esbroncar, escridassar» (Boyer 1839: 189; Fleming i Tibbins 1845: 1258). Per tant, és possible que Josep M. Bayarri el nominalitzara, amb la qual cosa titllava Fuster com algú que sempre renya, esbronca o escridassa. 
l’utilitza ací per justificar tots els homenatges possibles cap a «aquell qui exalsá la poesia vinculantla a Deu qe consagra poetes», mentre que cal obviar les opinions discrepants «d'esprits primmirats o crinillers», en una clara al lusió encoberta cap a l'assagista suecà -ara, almenys, dona un sinònim del mot «criniller» (1961c: 6). L'article acaba amb una arenga: «Conmemorem Llorente, sempre vigent en l'essencial, valencians!» (1961c: 6). De nou, no veiem cap rastre d'intent de reflexió en les paraules de Bayarri; només reivindica tot el que han fet per Llorente, a qui torna a lloar sense cap tipus d'anàlisi crítica.

\section{Unes conclusions a la polèmica}

Poc podia imaginar Joan Fuster que aquell article del 6 de juliol de 1961, «Llorente», en què pretenia abordar la figura del patriarca des d'un punt de vista crític i reflexiu, que servira d'excusa o de pretext per comentar la deserció de la nostra intel lectualitat cap als referents propis, girats completament cap als referents espanyols, poguera arribar a ofendre Josep M. Bayarri, el qual, però, s'havia quedat en la punta de l'iceberg. En la carta de Tots Sants del mateix 1961 de l'assagista de Sueca a Josep Garcia Richart, se sorprenia, sempre amb un punt irònic, d'aquell «descuit» que havia «provocat les ires públiques del senyor Bayarri» (2003: 312).

No cal dir que les diferències entre Joan Fuster i Josep M. Bayarri eren més que palpables, començant per l'aspecte generacional. El testimoni de Jaume Bru i Vidal, reportat per Faust Ripoll en tractar el panorama cultural valencià dels anys quaranta, és bastant il lustratiu:

\footnotetext{
Hi havia uns quants senyors que ja havien escrit algunes coses abans i després de la guerra, com Duran i Tortajada, Carles Salvador, Bernat Artola, Almela i Vives, Josep M. Bayarri, Xavier Casp... però eren molt distants i ens miraven per damunt del muscle als més joves: Joan Fuster, Vicent Andrés Estellés, Francesc Burguera, Maria Beneyto, o jo mateix (2010: 47).
}

Però no tan sols la distància d'edat els enquadrava en postures oposades, sinó, sobretot, la distància ideològica. El valencianisme promogut per Fuster, o fusterianisme (tot i que en el moment d'aquesta polèmica encara no havia aparegut Nosaltres, els valencians), era un valencianisme de caire intel lectual, que defensava que el País Valencià formava part d'una unitat, d'una superestructura més àmplia, fonamentada, a grans trets, en llaços històrics, culturals i lingüístics, juntament amb els altres territoris de parla catalana, és a dir, els Països Catalans. El valencianisme proposat per Bayarri, en canvi, era més aviat sentimental i, per tant, antiintel lectual, ${ }^{6}$ conservador i contrari a l'anterior,

6 Vicent Flor estudia l'antiintel lectualisme i el sentimentalisme del blaverisme (2011: 239-244), el qual s'apropià, d'entre d'altres personalitats, de Josep M. Bayarri, que fou nomenat «prohom» per Lo Rat Penat i considerat un dels seus «sants civils anticatalanistes» (2011: 145). No obstant això, el mateix Flor destaca que devia ser un personatge incòmode per al moviment blaver, atés que, a pesar del seu antipancatalanisme, s'hi mostrà -almenys quan publicà El perill catalá (1931) - catalanòfil, i, fins i tot, sobiranista i antiespanyol (2011: 27). Una mostra del mateix Bayarri, en què explicita la importància que dona al sentiment: «I el sentiment del poble, fort, insobornable, en la nostra Valencia, está 
que era més aviat modernitzador. Els fragments d'El perill catalá que, tot seguit, reproduïm són bastants explícits en aquest sentit:

\begin{abstract}
Havem de véncer la natural repugnancia i reseguir el camí mamprés i traçat previament per a, en son terme espandir aquell nostre sentiment d'orgull valencianesc i recolsats en el poble encara sá, perennement sá i iliteraturisat, franc i viril, fer el colofó del patriotisme valenciá ven viu, sempre viu, estroncant la morbosa bifurcació que s'intenta (1931: 66).

El sentiment popular valenciá que, com diem, és cosa inimposada no admet ni admetrá artifisis ni monstruositats deformadores ni suplantadores i restará vevent en les fonts naturals i tant que'ls inquiets valencians catalanisats i catalanisants, al no conseguir la satisfacció de somoure aquell sentiment en lo poble arrailat, decantantlo vers ses insensates apetencies (1931: 120).
\end{abstract}

Des d'aquest punt de vista, s'entén que Bayarri no poguera suportar que algú posara en dubte el paper de Llorente i la seua memòria en la societat valenciana, malgrat que la seua defensa només es basara en aspectes sentimentals («Commemorem Llorente, sempre vigent en l'essencial, valencians!»). Recordem, a més, que és gràcies a la glorificació de l'horta llorentina que es crearà el mite del valencià llaurador, treballador i honrat, apropiat, més endavant, pel blaverisme com a símbol d'aquest regionalismo bien entendido, en contraposició a la modernització ideològica, social i política propugnada per certs sectors intel lectuals (Flor 2011: 28). Josep M. Bayarri i Joan Fuster estaven, doncs, a les antípodes, fins al punt que, com exposa el mateix suecà, s'havien insultat en les pàgines de la premsa local en alguna ocasió; la darrera vegada que Bayarri l'interpel là fou el 1963, i demanava a les autoritats la crema d'un dels seus llibres, el Nosaltres, els valencians (Fuster 1971: 33).

Tanmateix, malgrat aquests enfrontaments i desqualificacions recíprocs, Joan Fuster respectava, ni que siga una mica només, com ell mateix matisa, Josep M. Bayarri (1971: 33). Per això, no és estrany que l'incloga entre els quatre poetes valencians -junt amb Miguel Duran de València, Daniel Martínez Ferrando i Jacint Maria Mustieles- que marcarien un lleuger i vacil lant canvi respecte al llorentinisme, primer a l'Antologia de la poesia valenciana (1900-1950) (1994: 46-47), i després a la Literatura catalana contemporània, concretament a la «Nota sobre el País Valencià» (1980: 276). Convindria recordar que aquesta darrera obra veié la llum després de la mort del poeta valencià. És a dir, que, a pesar de la separació ideològica entre l'un i l'altre, sembla que el de Sueca sí que en va saber veure allò que, per a ell, era salvable.

Més encara: ho demostra en la "pseudo-necrologia» titulada «Una mica de dol per J. M. Bayarri», publicada a Serra d'Or el febrer de 1971. Més enllà de la distància que marca amb el títol, aquesta «mica de» estaria condicionada per la relació, pel contacte personal, que Bayarri sempre havia mantingut amb la família de Fuster, de manera que la confrontació política i cultural no li impedia el respecte en l'esfera privada i personal. D'altra banda, l'assagista hi avalua el personatge no sols

manifestant cada día, continuament, sa força única i la calor cordial de la nacionalitat valenciana del poble valenciá.» (1931: 31). 
J. Àngel Cano Mateu. Teodor Llorente, cinquanta anys després: Una polèmica entre Joan Fuster i Josep M. Bayarri

pels resultats, sinó també per la sinceritat de les motivacions personals i pels condicionaments sociopolítics. En un moment determinat, li arriba a atribuir característiques d'heroi per la seua «aportació heroica» a la poesia catalana del País Valencià, o, fins i tot, gairebé de màrtir, ja que «no vacil là a sacrificar el seu jornal a la "devoció” lingüística» ni dubtà a «"traure’s el pa de la boca" [...] per abonar les factures d'impremta», així com justificar les tendències secessionistes com a mètode de «supervivència "literària" de la llengua» (1971: 33).

En resum, l'intercanvi d'articles ens serveix per comprovar les dues vies que el valencianisme de postguerra estava prenent: el valencianisme crític i modernitzador, d'una banda, i el valencianisme sentimentalista i irreflexiu, defensor dels tòpics, d'una altra. Quina postura pensava més en Llorente, quina era, al capdavall, més «llorentinòfila»: ¿la de Fuster, que, encara que considerà que com a líder de la Renaixença fracassà, sabé agrair a ell i als renaixencistes la tasca, i en demanava una reflexió sobre l'oblit de la societat valenciana al respecte; o la de Bayarri, content i pagat pels actes de commemoració que s'hi havien desenvolupat? La pregunta, lògicament, és retòrica.

\section{Bibliografia}

Bayarri, J. M. (1931) El perill catalá, València, Consell Valenciá de Publicacions.

Bayarri, J. M. (1961a) Cinquantenari llorentí, València, Imp. Marí Montañana.

Bayarri, J. M. (1961b) «Encara Llorente, i... sempre», Las Provincias, 14-X-1961, p. 7.

Bayarri, J. M. (1961c) «Commemorant Llorente», Jornada, 25-X-1961, p. 6.

Boyer, A. (1839) Boyer's French Dictionary, Boston, Hilliard, Gray and Co.

Carbó, F.; Simbor, V. (1993) La recuperació literària en la postguerra valenciana (1939-1972), València/ Barcelona, Institut Interuniversitari de Filologia Valenciana/Publicacions de l'Abadia de Montserrat.

Corbín Llorente, J. T. (2013) «Presentació», dins Roca, R. (ed.) Teodor Llorente: Obra Valenciana Completa, València, Acadèmia Valenciana de la Llengua, p. 17-25.

Fleming, C.; Tibbins, J. (1845) A new and complete French and English and English and French dictionary, on the basis of the Royal dictionary English and French and French and English, Filadèlfia, Carey and Hart.

Flor, V. (2011) Noves glòries a Espanya. Anticatalanisme i identitat valenciana, Catarroja/Barcelona, Afers.

Fuster, J. (1961a) «Llorente», Jornada, 6-VII-1961, p. 2.

Fuster, J. (1961b) «Defensa de Llorente», Jornada, 20-X-1961, p. 2. 
J. Àngel Cano Mateu. Teodor Llorente, cinquanta anys després: Una polèmica entre Joan Fuster i Josep M. Bayarri

Fuster, J. (1971) «Una mica de dol per J. M. Bayarri», Serra d’Or, febrer, p. 33.

Fuster, J. (1980 [1a ed. 1971]) Literatura catalana contemporània, Barcelona, Curial.

Fuster, J. (1994 [1a ed. 1954, ed. Selecta]) Antologia de la poesia valenciana (1900-1950), València, Eliseu Climent.

Fuster, J. (2003) Correspondència 6: Vicent Ventura, Josep Garcia Richart, València, 3 i 4.

Las Provincias (1911) «El entierro del Sr. Llorente», Las Provincias, 3-VII-1911, p. 1-2.

Llorente Falcó, T. (1930) Epistolari Llorente. Volum II: Cartes de llevantins (1901-1911), Barcelona, Balmes.

López-Pampló, G. (2012) «La conferència “Llorente i els infants” de Carles Salvador (1948). Estudi i transcripció», dins Roca, R. (ed.) Teodor Llorente, cent anys després, Alacant, Institut Interuniversitari de Filologia Valenciana, p. 153-207.

Ripoll, F. (2010) Valencianistes en la postguerra. Estratègies de supervivència i de reproducció cultural (19391951), Catarroja/Barcelona, Afers.

Roca, R. (2007a) Teodor Llorente, líder de la Renaixença valenciana, València, Publicacions de la Universitat de València.

Roca, R. (2007b) «Noves perspectives de la Renaixença valenciana», Anuari Verdaguer, 15, p. 411 433.

Roca, R. (2011) «La mort i l'herència», Levante. El Mercantil Valenciano, 01-VII-2011. Disponible en línia a: https://www.levante-emv.com/cultura/2011/07/01/mort-i-lherencia-teodorllorente/820761.html. [Consulta: 6 agost 2019].

Sanchis Guarner, M. (1968) La Renaixença al País Valencià. Estudi per generacions, València, 3 i 4.

Sanchis Sivera, J. (1911) «Biografía del laureado vate Teodoro Llorente y Olivares», Lo Rat-Penat. Revista Mensual, 7, p. 290-370.

Simbor, V. (1988) Els fonaments de la literatura contemporània al País Valencià (1900-1939), Barcelona, Institut Interuniversitari de Filologia Valenciana/Publicacions de l'Abadia de Montserrat.

Simbor, V. (1996) «Introducció», dins Llorente, T. Poesia, València, Institució Alfons el Magnànim, p. 7-35.

Simbor, V. (2012) «"La barraca” llorentina: la creació d'un tòpic literari contemporani», dins Roca, R. (ed.) Teodor Llorente, cent anys després, Alacant, Institut Interuniversitari de Filologia Valenciana, p. 91-121. 